\title{
Diversity of Bradyrhizobia in Subsahara Africa: A Rich Resource
}

\author{
Jann Lasse Grönemeyer and Barbara Reinhold-Hurek* \\ Department of Microbe-Plant Interactions, Faculty of Biology and Chemistry, Center for Biomolecular Interactions Bremen, \\ University of Bremen, Bremen, Germany
}

Making use of biological nitrogen fixation (BNF) with pulses and green manure legumes can help to alleviate nitrogen deficiencies and increase soil fertility, problems faced particularly in smallholder agriculture in Subsahara Africa (SSA). The isolation of indigenous rhizobia provides a basis for the formulation of rhizobial inoculants. Moreover, their identification and characterization contribute to the general understanding of species distribution and ecology. Here we discuss global species discovery of Bradyrhizobium spp. Although recently the number of validly published Bradyrhizobium species is rapidly increasing, their diversity in SSA is not well-represented. We summarize the recent knowledge on species diversity in the Bradyrhizobium yuanmingense lineage to which most SSA isolates belong, and their biogeographic distribution and adaptations. Most indigenous rhizobia appear to differ from species found on other continents. We

OPEN ACCESS

Edited by:

Marco Bazzicalupo,

Università degli Studi di Firenze, Italy

Reviewed by:

Gilles Bena,

Institut de Recherche pour le Développement (IRD), France

Aregu Amsalu Aserse,

University of Helsinki, Finland

*Correspondence:

Barbara Reinhold-Hurek

breinhold@uni-bremen.de

Specialty section:

This article was submitted to

Microbial Symbioses,

a section of the journal

Frontiers in Microbiology

Received: 01 May 2018

Accepted: 27 August 2018

Published: 20 September 2018

Citation:

Grönemeyer JL and Reinhold-Hurek B (2018) Diversity of Bradyrhizobia in Subsahara Africa: A Rich Resource.

Front. Microbiol. 9:2194.

doi: 10.3389/fmicb.2018.02194 stress that an as yet hidden diversity may be a rich resource for inoculant development in future. As some species are exceptionally temperature tolerant, they may be potential biofertilizer candidates for global warming scenarios.

Keywords: Bradyrhizobium, diversity, Subsahara Africa, Namibia, inoculant, temperature tolerance

\section{INTRODUCTION}

In the past 50 years, increases in crop yield have been striking in some regions, e.g., particularly rice yields in Asia, due to green revolution. However, this high-input approach has been less successful in Sub-Saharan Africa (SSA) with its hugely variable environmental, climatic and cultural conditions (Rudebjer et al., 2013). The predominant agricultural practice based on improved varieties of common staple crops in high-input systems has not well-succeeded to address food insecurity and malnutrition in Sub-Saharan Africa, where the prevalence of undernourishment is still at 20.8\%, not having decreased since 2010 (FAO, 2017). As exemplified for many SSA areas, agriculture in the Okavango region is largely dominated by smallholder and subsistence farming. Recent surveys conducted at sites in Angola, Namibia and Botswana revealed that 99, 88, and 59\% of the households, respectively, practice arable agriculture (Domptail et al., 2013; Große et al., 2013; Kowalski et al., 2013). Variability of yields, risk for crop failure, limited financial resources, and low-fertility N-poor soils are among the contributing factors to food insecurity in these rainfed agriculture systems (Pröpper et al., 2010). These risks are predicted to increase in SSA due to climate change. Projections of consequences of climate change at the local scale indicated that the Kavango basin will become warmer $\left(1.5-2.5^{\circ} \mathrm{C}\right)$, and obtain less mean annual precipitation $(50-100 \mathrm{~mm})$ until 2045 (Pröpper et al., 2015).

Making use of biological nitrogen fixation (BNF) of root nodule symbioses with pulses and legume green manure can help to alleviate nitrogen deficiencies and increase soil fertility 
(Pule-Meulenberg et al., 2010). The application of rhizobial inoculant carrying highly effective rhizobia can boost BNF and is regarded as a cost-effective and sustainable approach to increase yields in N-limited agricultural systems with low productivity (Dakora and Keya, 1997; Mpepereki and Pompi, 2003). However, established inoculant strains often fail when transferred to regions featuring environmental conditions dissimilar to their original habitat, presumably due to poor persistence and competitiveness (Roughley, 1970; Mpepereki and Pompi, 2003; Zhang et al., 2003; Law et al., 2007). Many agriculturally important legumes enter a symbiotic association with rhizobia of the genus Bradyrhizobium. Especially pulses commonly used by smallholders in SSA, cowpea (Vigna unguiculata), Bambara groundnut (Vigna subterranea), and peanut (Arachis hypogaea), are nodulated by Bradyrhizobium spp. Here, we will first highlight that the diversity of bradyrhizobia - as potential adapted inoculants - is largely underexplored in SSA, and provide recent insights into their biogeography and diversity.

\section{GLOBAL SPECIES DISCOVERY OF BRADYRHIZOBIUM SPP.}

For a long time the species diversity inside Bradyrhizobium remained underexplored due to the exceptional conservation of the 16S rRNA gene sequence that is routinely used as a marker for species discrimination (van Berkum and Fuhrmann, 2000). The high genospecies diversity inside Bradyrhizobium was first discovered in a DNA-DNA hybridization study by Willems et al. (2001). With the help of alternative markers and multilocus sequence analysis (MLSA) (Stepkowski et al., 2005; Vinuesa et al., 2005b), species delineation became more feasible. Now the number of validly published bradyrhizobial species is rapidly increasing since 2012 (Figure 1) and currently counting 42 validly published species, more than half of which have been published since 2014 (Parté, 2014; de Lajudie and Young, 2017). Approximately one third of the described species originates from South America, one third from other regions, and a large number from China, while only few originate from SSA (Figure 1). As yet, only five species from SSA have been published: Bradyrhizobium kavangense (Grönemeyer et al., 2015b), Bradyrhizobium namibiense (Grönemeyer et al., 2017), Bradyrhizobium subterraneum (Grönemeyer et al., 2015a), Bradyrhizobium vignae (Grönemeyer et al., 2016), and "Bradyrhizobium shewense" (Aserse et al., 2017). Thus, only few genotypes for development of effective inoculants for agricultural crops are taxonomically well-described and thereby well-comparable.

Within the sub-Saharan regions, the plant species richness and endemism is particularly high in the Cape Floristic Region, the East Coast near Mozambique, and the Congo-Zambezi watershed (Linder, 2001). Among Leguminosae / Fabaceae, roughly 1,500 were yet alone considered in Southern Africa (Trytsman et al., 2016). SSA being the center of origin for many legumes, these regions might entail a high diversity of effective microsymbionts (Pule-Meulenberg, 2014). The full potential of SSA indigenous legumes may not yet have been recognized, although they can be predicted as valuable germbank for possible agricultural use in arid and semi-arid regions (Sprent et al., 2010). Uncovering the full diversity and species richness of the respective symbionts may provide a vast resource for inoculant development for legume crops and forage plants. As especially in these regions, smallholder farming is widespread that could greatly profit from adapted inoculant technology, future research should focus on unraveling the putative biodiversity of rhizobia and particularly Bradyrhizobium in SSA.

\section{PUTATIVE BRADYRHIZOBIUM DIVERSITY TO BE UNCOVERED IN SSA}

The increased number of bradyrhizobial species allowed several studies to uncover a geographic distribution. Most of our knowledge about rhizobia and their biogeography is based on studies conducted in Asia, Europe and the Americas (PuleMeulenberg, 2014). Information on SSA rhizobia is limited despite SSA regions presumably entail a high microsymbiont diversity that is favored by at least three factors: First, SSA is characterized by heterogeneous soils and climates, providing diverse habitats (Petersen et al., 2010; Gröngröft et al., 2013; Wade et al., 2014). Second, rhizobial diversity may be higher in arid and semi-arid regions frequently found in SSA, as observed for Senegal (Wade et al., 2014) or Brazil (Martins et al., 1997). It has been suggested that the selection pressure on rhizobia may lead to the evolution of stress tolerant strains which could partly explain the increased diversity observed in water limited environments. Third, Africa is the center of origin of many legumes (including cowpea and Bambara groundnut) and a rich diversity of wild legume species exists (Pule-Meulenberg, 2014; Lemaire et al., 2015).

The tribe Crotalarieae, for instance, is largely endemic to SSA (14 endemic genera comprising over 1,000 species) and known for its high microsymbiont diversity, including Bradyrhizobium, Rhizobium, Methylobacterium, Microvirga, Mesorhizobium, Ensifer, and Burkholderia (Aserse et al., 2012; Sprent et al., 2013; Ndungu et al., 2018). Earlier studies using DNA fingerprinting already indicated a high microsymbiont diversity in SSA regions (Botha et al., 2004; Law et al., 2007). To date, only a small number of surveys used MLSA to uncover the microsymbiont diversity in SSA. The few studies focusing on "cowpea group" rhizobia (from agricultural plants) spanned the countries of Botswana and South Africa (Steenkamp et al., 2008), Botswana, South Africa, and Ghana (Pule-Meulenberg et al., 2010), Senegal (Wade et al., 2014), Namibia and Angola (Grönemeyer et al., 2014), Ghana and South Africa (Puozaa et al., 2017), Mozambique (Chidebe et al., 2018), Kenya (Ndungu et al., 2018), and Ethiopia (Degefu et al., 2018). Their main findings were in general agreement: First, almost all detected genotypes presumably represented yet unknown species (Steenkamp et al., 2008; Grönemeyer et al., 2014; Wade et al., 2014; Degefu et al., 2018). Second, genotype occurrence strongly relied on the geographic location (Steenkamp et al., 2008; Pule-Meulenberg et al., 2010; Grönemeyer et al., 2014; Wade et al., 2014). Third, the highly diverse genotypes were mainly assigned to a sub-generic group, 


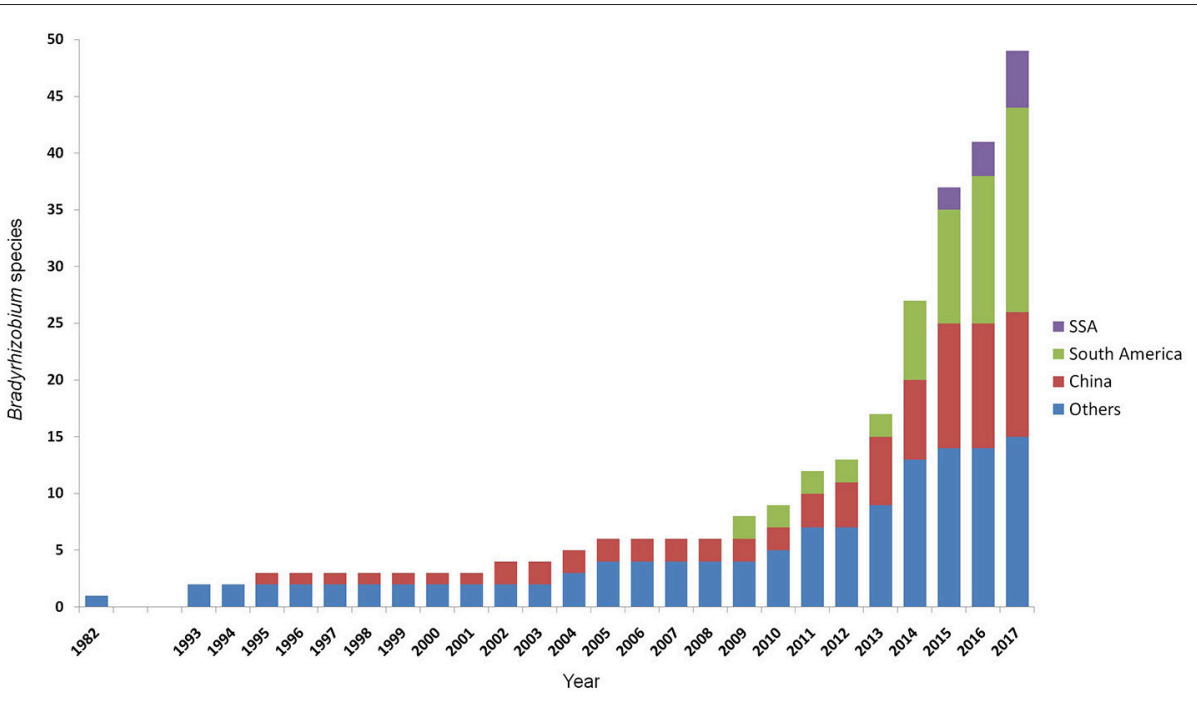

FIGURE 1 | Increase of described species of the genus Bradyrhizobium with time. Data includes all species officially listed (Parté, 2014; de Lajudie and Young, 2017), and the effectively, but not validly, published species "B. arachidis," "B. valentinum," "B. brasilense," "B. sacchari," "B. centrolobii," "B. macuxiense," and "B. shewense" (Wang et al., 2013; Durán et al., 2014; Aserse et al., 2017; da Costa et al., 2017; de Matos et al., 2017; Michel et al., 2017).

the Bradyrhizobium yuanmingense lineage (Wade et al., 2014), forming a clade with $B$. vignae and B. subterraneum, but not to the sub-generic group of Bradyrhizobium japonicum (Steenkamp et al., 2008; Grönemeyer et al., 2014; Wade et al., 2014).

The expectation of high bradyrhizobial species diversity from agricultural plants in SSA is supported by the phylogeny of published isolates of the abovementioned studies (Figure 2). Matching the previous findings, many isolates form distinct phylogenetic clusters and could not be assigned to recognized species. In the rare cases where African genotypes cluster with named species, sequence divergence is high, indicating different genospecies affiliations. Thus most indigenous rhizobia appear to differ from species found on other continents.

The observed high rhizobial diversity entails the discovery of yet unknown species. Remarkably is, however, that recognized species are virtually absent in SSA. Apart from the geographic location, this observation might be related to the natural selectivity of the sampled legume hosts and the lack of taxonomic studies. Relatively few studies focused on natural microsymbionts of cowpea and especially Bambara groundnut (Pule-Meulenberg, 2014; Puozaa et al., 2017). The first validly published species from this host, B. subterraneum (Grönemeyer et al., 2015a) was mainly isolated from Bambara groundnut, and also from peanut. Though the number of studies is limited, Bambara groundnut is apparently a promiscuous host. In our cross-inoculation experiments, almost the whole spectrum of tested bradyrhizobia, including reference species, induced effective nodulation on Bambara groundnut (Grönemeyer et al., 2014). Only five out of 26 cowpea rhizobia failed to nodulate Bambara groundnut in a study in Zimbabwe (Mpepereki et al., 1996), albeit indicating a certain degree of selectivity. Most other detected phylotypes include isolates from cowpea. This is not surprising since cowpea is one of the most promiscuous legumes (Lewin et al., 1987; Bala and Giller, 2001). Cowpea rhizobia collections are usually highly diverse (Grönemeyer et al., 2014; Wade et al., 2014), and several studies even reported strains from genera other than Bradyrhizobium to nodulate cowpea (Mpepereki et al., 1996; Martins et al., 1997). Hence, cowpea isolates obtained at a specific site largely reflect the local abundance of competitive bradyrhizobial microsymbionts, providing a solid basis to study bradyrhizobial biodiversity. Several studies surveyed the rhizobial diversity associated with cowpea in China (Zhang et al., 2008), India (Appunu et al., 2009), Japan (Sarr et al., 2011), Mexico (Ormeno-Orrillo et al., 2012), and Spain (Bejarano et al., 2014). In contrast to African studies, phylotypes could be clearly assigned to named species. Almost all cowpea isolates from Japan represented either B. japonicum, Bradyrhizobium diazoefficiens, B. yuanmingense, or Bradyrhizobium elkanii, whereas B. yuanmingense dominated in India and Bradyrhizobium cytisi and Bradyrhizobium canariense in Spain, for instance.

\section{LINKAGE OF GENOTYPE OCCURRENCE AND GEOGRAPHIC LOCATION}

The increased number of bradyrhizobial species allowed several studies to uncover a geographic distribution, and biogeography could be linked to different variables such as climate (Vinuesa et al., 2008; Risal et al., 2010; Adhikari et al., 2012), soil pH (Li et al., 2011; Adhikari et al., 2012), water regime (Wade et al., 2014), salinity and soil potassium content (Zhang et al., 2011; Chen et al., 2016), and geographic isolation (Stepkowski et al., 2012). Biogeography is apparently related to adaptations at multiple levels, ranging from climate to micro niche (Wade et al., 2014), and a biogeographic distribution of SSA isolates from agricultural plants is also reflected in Figure 2. A survey on the impact of climate, for instance, indicated that $B$. japonicum, B. canariense, and B. yuanmingense are mainly 


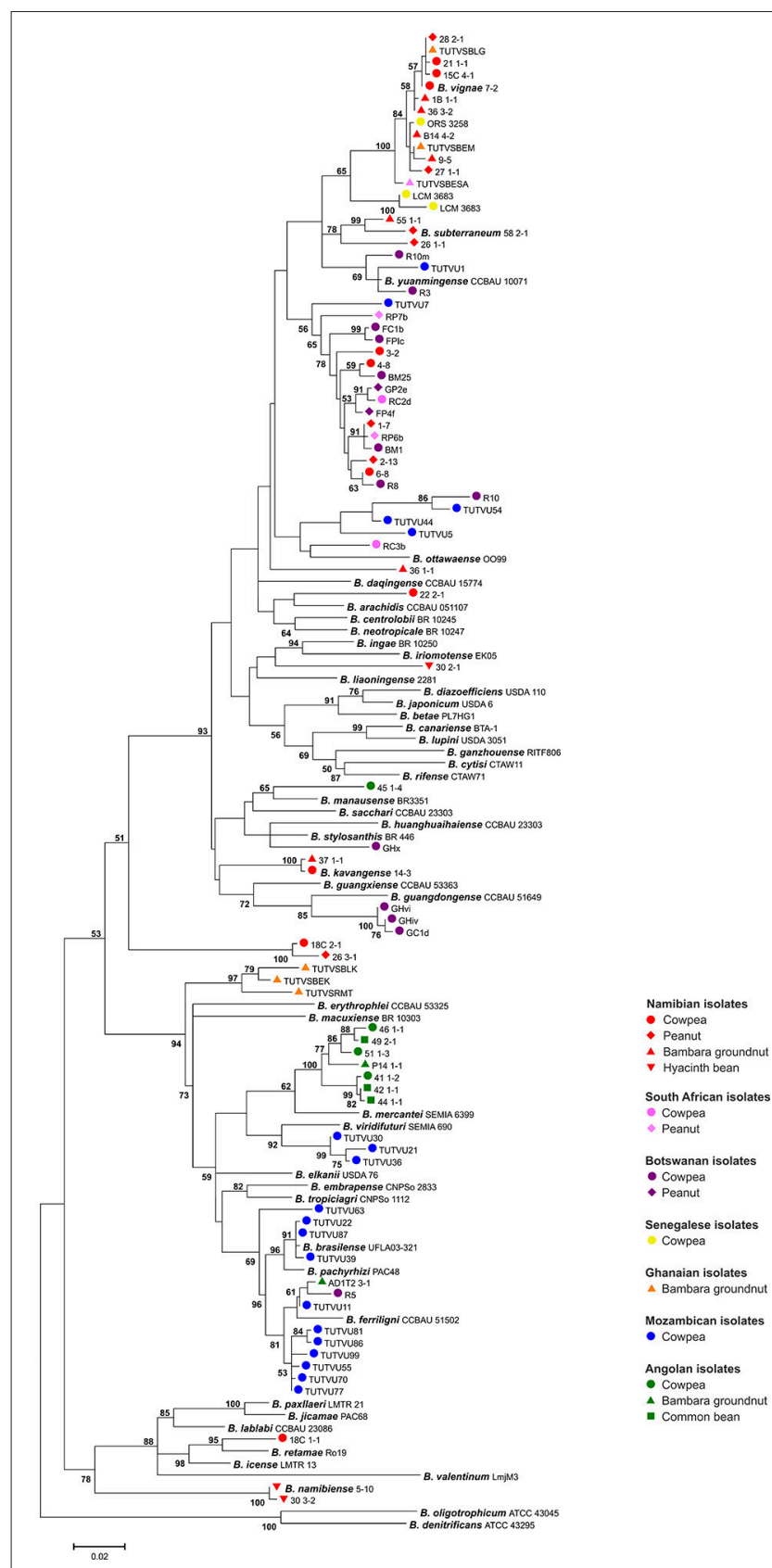

FIGURE 2 | Maximum likelihood-based phylogeny inferred from glnll-recA sequences of SSA bradyrhizobia and species type strains. SSA isolates from agricultural plants (see legend) obtained in five African studies are represented (Steenkamp et al., 2008; Grönemeyer et al., 2014; Wade et al., 2014; Puozaa et al., 2017; Chidebe et al., 2018). Considerably shorter sequences were excluded, and representatives were selected for identical sequences. The tree was calculated from 751 positions using the General Time Reversible model. A bootstrap value is indicated when the associated taxa clustered together in $\geq 50 \%$ of 500 pseudoreplicates. The scale bar indicates the number of substitutions.

found in temperate regions in the Northern Hemisphere, in Mediterranean regions, or in the subtropics and tropics, respectively (Vinuesa et al., 2008). Consistently, B. japonicum was shown to be less competitive in soybean nodulation under higher temperatures (Suzuki et al., 2014). The relevance of adaptation at a more local level is indicated by the prevalent detection of Bradyrhizobium liaoningense in alkaline soils ( $\mathrm{Li}$ et al., 2011; Adhikari et al., 2012), contrasting both Bradyrhizobium pachyrhizi and $B$. canariense that are primarily found in acid soils (Vinuesa et al., 2005a; Grönemeyer et al., 2014). Species abundance might be further conditioned by physico-chemical parameters like soil osmotic strength, as indicated in a recent survey in Senegal (Wade et al., 2014).

Thus, the assignment of a bradyrhizobial strain to a distinct species can generate information on adaptational properties, which in turn account for a strain's suitability to serve as inoculant at a particular site. As species delineation is mainly based on similarity of conserved genes differences, adaptational properties may be further refined by accessory genes. To date, however, information on bradyrhizobial species biogeography in SSA regions is limited. Species may be restricted to certain geographic locations, but others may have spread among multiple regions and continents, with soil-contaminated seeds or artificial inoculation facilitating long-distance dispersal (Perez-Raminez et al., 1998). Host control and preferential selection can provide competitive advantages and thus constitute key drivers for the successful invasion into new geographic regions, especially when rhizobia and their hosts were co-introduced (Heath and Tiffin, 2009; Porter et al., 2011; Hollowell et al., 2016).

The uniqueness of SSA rhizobia might rather be attributed to their exclusion or the enrichment of other species by more selective and better studied legumes of temperate regions. However, many SSA rhizobia were found to possess the genomic background to produce highly decorated Nod factors, presumably allowing a broad host-range (Steenkamp et al., 2008). Nod factors are lipochitooligosaccharides "decorated" by diverse modifications, that induce early responses of the symbiotic interation in the legume host. Symbiotic genes are readily exchanged between bradyrhizobial species (Horn et al., 2014; Hollowell et al., 2016). Moreover, most bradyrhizobial lineages feature a broad host range, without strong barriers to adapt their chromosomal backgrounds to novel hosts (Parker, 2015). Consequently, host plant selectivity may in general have a minor impact on species abundance (Hollowell et al., 2016), and it is more likely that the observed biogeography is due to an adaptation of species to soil-climatic factors. Consistently, many cowpea and Bambara groundnut isolates effectively nodulate peanut and hyacinth bean (Grönemeyer et al., 2014). Thus, the range of sampled legume hosts is obviously not a major determinant of the observed species uniqueness.

Alternatively, unique soil-climatic conditions in SSA might have played a major role, according to the Baas-Becking hypothesis "everything is everywhere, but the environment selects." However, several studies in SSA explored the rhizobial diversity under highly variable soil-climatic conditions (Grönemeyer et al., 2014; Wade et al., 2014). Moreover, several regions in southern Africa and Australia exhibit very similar soils and climates, as illustrated by the issue that weeds are easily exchanged (Kottek et al., 2006; Sprent et al., 2013). Nevertheless, their native floras are very different (Sprent et al., 2013). Consequently, geographic isolation and adaptation of 
rhizobia to various soil-climatic conditions and undomesticated legume hosts might have favored the evolution of diverse endemic species. Geographic isolation of SSA rhizobia was indicated in a previous study (Steenkamp et al., 2008): The authors found that, despite being extensively exchanged via horizontal gene transfer, all bradyrhizobial nodA sequences detected in SSA cluster in one of the seven recognized major clades (Stepkowski et al., 2007), contrasting Asian and American (but not European) nodA sequences which distribute over various clades. Recently, $16 \operatorname{nod} A$ clades have been described, where clade III with the majority of SSA isolates is cosmopolitan, members being widespread in sub-Saharan Africa, the Americas, Australia and in southern and eastern Asia (Aserse et al., 2012; Beukes et al., 2016). Since the clade II strains include North African and European ones the African nodA clade might be ancient and spread to other continents until the Sahara desert formed. The resulting geographic isolation then prevented the import of nodA lineages (or rhizobial species) that evolved on other continents (Stepkowski et al., 2007). Conversely, species which evolved in SSA did not spread to other continents and were thus not detected in the many surveys conducted outside Africa.

\section{TEMPERATURE TOLERANCE OF BRADYRHIZOBIA IN GLOBAL CLIMATE CHANGE SCENARIOS?}

Geographic distribution might also be explained by adaptation at higher levels such as regional climatic conditions (Vinuesa et al., 2008; Wade et al., 2014). An initial survey using multilocus sequence analysis to assess bradyrhizobial biogeography found that B. japonicum, B. diazoefficiens (former B. japonicum Ia, Delamuta et al., 2013), and B. elkanii are very widespread across the Northern Hemisphere and are thus detected in more temperate regions (Vinuesa et al., 2008). Most studies

TABLE 1 | Maximum growth temperature (MGT) and geographic occurrence of selected Bradyrhizobium species and African phylotypes.

\begin{tabular}{|c|c|c|}
\hline Species/Phylotype & $\mathrm{MGT}^{\mathrm{a}}$ & Occurrence $^{b}$ \\
\hline B. vignae & $40^{\circ} \mathrm{C}$ & Namibia (Kavango), Senegal, Ghana, Southern India, Northern Australia \\
\hline B. subterraneum & $38^{\circ} \mathrm{C}$ & Namibia (Kavango), Botswana (Notwane), South Africa (Taung), Northern Australia (Kununurra), Western Australia (Carnarvon), Peru \\
\hline B. kavangense & $38^{\circ} \mathrm{C}$ & Namibia (Kavango) \\
\hline $222-1$ & $38^{\circ} \mathrm{C}$ & Namibia (Kavango), Northeastern Brazil (Bahia), Argentina (Cordoba) \\
\hline $451-4$ & $38^{\circ} \mathrm{C}$ & Angola \\
\hline B. yuanmingense & $38^{\circ} \mathrm{C}$ & $\begin{array}{l}\text { China (Hebei, Anhui, Sichuan, Hubei, Peking, Guangxi, Xinjiang, Henan, Laixi Country, Jiangsu), Taiwan, India (Thar desert, Madhya } \\
\text { Pradesh, Tamil Nadu, Karnataka, Andhra Pradesh), Thailand (Uttradit, Lampang), Myanmar (Shan State), Vietnam, Southern Japan } \\
\text { (Okinawa) Northern Australia (Kununurra), Bostwana (Rasesa), Northern Peru, Northern Ghana, South Africa (Taung), Senegal, and } \\
\text { more }\end{array}$ \\
\hline $18 C 2-1 / 263-1$ & $38^{\circ} \mathrm{C}$ & Namibia (Kavango) \\
\hline B. namibiense & $37^{\circ} \mathrm{C}$ & Namibia (Kavango) \\
\hline B. ganzhouense ${ }^{\mathrm{C}}$ & $37^{\circ} \mathrm{C}$ & Southern China (Ganzhou) \\
\hline $361-1^{c}$ & $35^{\circ} \mathrm{C}$ & Namibia (Kavango) \\
\hline SA-3 (3-2/1-7) & $35^{\circ} \mathrm{C}$ & $\begin{array}{l}\text { South Africa (Roodeplaat, Taung), Botswana (Maun, Rasesa, Francistown, Gaborone), Namibia (Kavango), Ethiopia,Senegal, } \\
\text { Southern China }\end{array}$ \\
\hline B. diazoefficiens & $<37^{\circ} \mathrm{C}$ & $\begin{array}{l}\text { USA (North Carolina, Maryland, Mississippi, lowa), Canada (Quebec, Ontario), Japan (Kyushu, Yamagata, Fukushima, Kumamoto, } \\
\text { Hokkaido, Kagoshima, Miyagi, Niigata), China (Heilongjiang, Chengdu, Hubei, Anhui, Guangdong, Guangxi), Nepal (Kathmandu, } \\
\text { Khumaltar, Khadichaur), Brazil, and more }\end{array}$ \\
\hline B. japonicum & $<37^{\circ} \mathrm{C}$ & $\begin{array}{l}\text { Japan, China (Heilongjiang, Chengdu, Guangdong, Guangxi, Sichuan, Anhui), Nepal (Kathmandu), USA (Mississippi, Maryland), } \\
\text { Canada (Ontario, Quebec), Argentina, Brazil, South Africa (Mpumlanga) }\end{array}$ \\
\hline B. Iupinic & $<37^{\circ} \mathrm{C}$ & $\begin{array}{l}\text { USA (Georgia, California), Spain (Canary Islands, Llombai), Northern Tunisia, Southern Australia (Esperance, Carrabin), England } \\
\text { (Rothamsted Research) }\end{array}$ \\
\hline $302-1$ & $<35^{\circ} \mathrm{C}$ & Namibia (Kavango), Southern India (Karnataka) \\
\hline $511-3 / 421-1$ & $<35^{\circ} \mathrm{C}$ & Angola, Malaysia (Luasong), Southeastern Brazil (Seropedica), Mexico (Veracruz) \\
\hline $\mathrm{GH} x^{\mathrm{C}}$ & Unknown & South Africa, Mexico (Veracruz) \\
\hline $\mathrm{GHiv}^{\mathrm{C}}$ & Unknown & South Africa \\
\hline TUTVSBEK ${ }^{C}$ & Unknown & Ghana, Mozambique, South Africa, Nigeria, Ethiopia, Southern China, Myanmar, Taiwan, India, USA, and more \\
\hline TUTVU36 & Unknown & Mozambique, Venezuela, Brazil, Mexico \\
\hline AD1T2 3-1 & Unknown & Angola, South Africa, Ethiopia, Ivory Coast, Brazil, Argentina, Mexico, China, Malaysia \\
\hline TUTVU77c & Unknown & $\begin{array}{l}\text { Mozambique, South Africa, Ethiopia, Brazil (Porto Trombetas), Mexico, Costa Rica, Malaysia (Luasong), South Korea (Cheongju), } \\
\text { China, Myanmar, USA (North Carolina), Canada (Quebec) }\end{array}$ \\
\hline
\end{tabular}

aData from Grönemeyer et al. (2014) and Delamuta et al. (2013).

${ }^{b}$ Based on ITS and glnll sequence identities of $\geq 98 \%$ in Genbank.

${ }^{c}$ No ITS sequence data available. 
conducted in SSA (see also Figure 2) pointed out that indigenous rhizobia were not assigned to the clade of $B$. japonicum. $B$. japonicum presumably evolved in regions outside SSA. Here, it adapted to more temperate and wet regions, thus probably lacking the prerequisite of higher level adaptation to many African climates. Moreover, a survey on soybean rhizobia along a climate gradient in Nepal revealed that roughly half of the isolates from temperate regions were related to B. japonicum, which was absent in subtropical regions (Risal et al., 2010). Indeed, the temperature tolerance for growth of Bradyrhizobium spp. varies greatly. Table 1 compares published maximum growth temperatures with geographic distribution, indicating that B. japonicum and closely related $B$. diazoefficiens and Bradyrhizobium lupini are all widespread in more temperate regions of both hemispheres, while phylotypes from warmer climates show a higher temperature tolerance. Many strains of B. japonicum grow best at $28^{\circ} \mathrm{C}$ (Munévar and Wollum, 1981). The genus Bradyrhizobium was indicated to optimally grow at $25-30^{\circ} \mathrm{C}$, maximal $33-35^{\circ} \mathrm{C}$ (Kuykendall, 2005). In contrast, many SSA phylotypes still grow at $38^{\circ} \mathrm{C}, B$. vignae exhibiting an exceptional high temperature tolerance growing above $40^{\circ} \mathrm{C}$ (Table 1; Grönemeyer et al., 2014, 2016). The known geographic range of $B$. vignae includes regions Namibia, Senegal, also Ghana and South Africa (Puozaa et al., 2017), Southern India and Northern Australia (Table 1 and Figure 2). A common feature of the regions may be climatic conditions. According to the Köppen-Geiger climate classification (Kottek et al., 2006), strikingly, climate of Namibia and Senegal is largely categorized as BSh (arid to semi-arid, steppe climate, hot), and Ghana, Southern India and Northern Australia are classified as Aw (tropical; hot with pronounced dry seasons). Thus, B. vignae is probably competitive in hot regions with seasonal drought, matching its exclusively high temperature tolerance. Furthermore, another phylotype cluster SA-3 (Steenkamp et al., 2008) represented by e.g., strain 1-7 from Namibia (Figure 2) intermingled with isolates obtained from Botswana and South

\section{REFERENCES}

Adhikari, D., Kaneto, M., Itoh, K., Suyama, K., Pokharel, B. B., and Gaihre, Y. K. (2012). Genetic diversity of soybean-nodulating rhizobia in Nepal in relation to climate and soil properties. Plant Soil 357, 131-145. doi: 10.1007/s11104-012-1134-6

Appunu, C., N'Zoue, A., Moulin, L., Depret, G., and Laguerre, G. (2009). Vigna mungo, $V$. radiata and $V$. unguiculata plants sampled in different agronomical-ecological-climatic regions of India are nodulated by Bradyrhizobium yuanmingense. Syst. Appl. Microbiol. 32, 460-470. doi: 10.1016/j.syapm.2009.05.005

Aserse, A. A., Räsänen, L. A., Aseffa, F., Hailemariam, A., and Lindström, K. (2012). Phylogenetically diverse groups of Bradyrhizobium isolated from nodules of Crotalaria spp., Indigofera spp., Erythrina brucei and Glycine max growing in Ethiopia. Mol. Phylogenet. Evol. 65, 595-609. doi: 10.1016/j.ympev.2012.07.008

Aserse, A. A., Woyke, T., Kyrpides, N. C., Whitman, W. B., and Lindström, K. (2017). Draft genome sequences of Bradyrhizobium shewense sp. nov. ERR $11^{\mathrm{T}}$ and Bradyrhizobium yuanmingense CCBAU $10071^{\mathrm{T}}$. Stand. Genomic Sci. 12:74. doi: 10.1186/s40793-017-0283-x

Bala, A., and Giller, K. E. (2001). Symbiotic specificity of tropical tree rhizobia for host legumes. New Phytol. 149, 495-507. doi: 10.1046/j.1469-8137.2001.00059.x
Africa, as implying that this heterogeneous cluster is widespread in parts of southern Africa. Climate in Botswana is mostly given the same category as the Okavango region, and occurrence extends to regions of warm climate such as Senegal, Ethiopia, and Southern China (Table 1). Especially in regions with periodic harsh heat, temperature tolerance may be a decisive advantage in competition with other rhizobia, ensuring better persistence in soils.

\section{PROSPECTS}

It became apparent that the vast diversity of Bradyrhizobium species in SSA is as yet underestimated. As regional strains may be developed into adapted inoculants for pulses and green manure, research in diversity, and characterization of nodule symbionts in SSA should be intensified. Particularly the high temperature tolerance of some African Bradyrhizobium species makes them potential candidates for application in global climate change scenarios that predict temperature increases. Future research should also address the molecular basis for the unusual temperature tolerance.

\section{AUTHOR CONTRIBUTIONS}

Both authors wrote the manuscript. JG reviewed the literature, gathered the information about species distribution and prepared the figures. BR-H organized the manuscript content.

\section{FUNDING}

The research was supported by a grant by the BMBF (Federal Ministry of Education and Research) in the framework of the project TFO: The Future Okavango (01LL0912G), SASSCAL: Southern African Science Service Centre for Climate Change and Adaptive Land Management (01 LG 1201D), and TOPSOIL (01DG17004A-1) to BR-H and Thomas Hurek.

Bejarano, A., Ramirez-Bahena, M. H., Velazquez, E., and Peix, A. (2014). Vigna unguiculata is nodulated in Spain by endosymbionts of Genisteae legumes and by a new symbiovar (vignae) of the genus Bradyrhizobium. Syst. Appl. Microbiol. 37, 533-540. doi: 10.1016/j.syapm.2014. 04.003

Beukes, C. W., Stepkowski, T., Venter, S. N., Clapa, T., Phalane, F. L., le Roux, M. M., et al. (2016). Crotalarieae and Genisteae of the South African Great Escarpment are nodulated-by novel Bradyrhizobium species with unique and diverse symbiotic loci. Mol. Phylogenet. Evol. 100, 206-218. doi: 10.1016/j.ympev.2016.04.011

Botha, W. J., Jaftha, J. B., Bloem, J. F., Habig, J. H., and Law, I. J. (2004). Effect of soil bradyrhizobia on the success of soybean inoculant strain CB 1809. Microbiol. Res. 159, 219-231. doi: 10.1016/j.micres.2004.04.004

Chen, J., Hu, M., Ma, H., Wang, Y., Wang, E. T., Zhou, Z., et al. (2016). Genetic diversity and distribution of bradyrhizobia nodulating peanut in acid-neutral soils in Guangdong Province. Syst. Appl. Microbiol. 39, 418-427. doi: 10.1016/j.syapm.2016.06.002

Chidebe, I. N., Jaiswal, S. K., and Dakora, F. D. (2018). Distribution and phylogeny of microsymbionts associated with cowpea (Vigna unguiculata) nodulation in three agroecological regions of mozambique. Appl. Environ. Microbiol. 84, e01712-17. doi: 10.1128/AEM.01712-17 
da Costa, E. M., Guimarães, A. A., Vicentin, R. P., Ribeiro, P. R. D., Leão, A. C. R., Balsanelli, E., et al. (2017). Bradyrhizobium brasilense sp nov., a symbiotic nitrogen-fixing bacterium isolated from Brazilian tropical soils. Arch. Microbiol. 199, 1211-1221. doi: 10.1007/s00203-017-1 390-1

Dakora, F. D., and Keya, S. O. (1997). Contribution of legume nitrogen fixation to sustainable agriculture in Sub-Saharan Africa. Soil Biol. Biochem. 29, 809-817. doi: 10.1016/S0038-0717(96)00225-8

de Lajudie, P. M., and Young, P. P. W. (2017). International Committee on Systematics of Prokaryotes Subcommittee for the Taxonomy of Rhizobium and Agrobacterium minutes of the meeting, Budapest, 25 August 2016 Int. J. Syst. Evol. Microbiol. 67, 2485-2494. doi: 10.1099/ijsem.0.002144

de Matos, G. F., Zilli, J. E., de Araujo, J. L. S., Parma, M. M., Melo, I. S., Radl, V., et al. (2017). Bradyrhizobium sacchari sp. nov., a legume nodulating bacterium isolated from sugarcane roots. Arch. Microbiol. 199, 1251-1258. doi: 10.1007/s00203-017-1398-6

Degefu, T., Wolde-Meskel, E., and Rasche, F. (2018). Genetic diversity and symbiotic effectiveness of Bradyrhizobium strains nodulating selected annual grain legumes growing in Ethiopia. Int. J. Syst. Evol. Microbiol. 68, 449-460. doi: 10.1099/ijsem.0.002486

Delamuta, J. R., Ribeiro, R. A., Ormeno-Orrillo, E., Melo, I. S., Martinez-Romero, E., and Hungria, M. (2013). Polyphasic evidence supporting the reclassification of Bradyrhizobium japonicum group Ia strains as Bradyrhizobium diazoefficiens sp. nov. Int. J. Syst. Evol. Microbiol. 63, 3342-3351. doi: 10.1099/ijs.0.049130-0

Domptail, S., Große, L. M., Kowalski, B., and Baptista, J. (2013). Cusseque/Cacuchi-The people. Biodivers. Ecol. 5, 73-80. doi: 10.7809/b-e. 00250

Durán, D., Rey, L., Navarro, A., Busquets, A., Imperial, J., and Ruiz-Argueso, T. (2014). Bradyrhizobium valentinum sp. nov., isolated from effective nodules of Lupinus mariae-josephae, a lupine endemic of basic-lime soils in Eastern Spain. Syst. Appl. Microbiol. 37, 336-341. doi: 10.1016/j.syapm.2014.05.002

FAO, IFAD, UNICEF, WFP, and WHO. (2017). The State of Food Security and Nutrition in the World 2017. Building Resilience for Peace and Food Security. Rome: FAO.

Grönemeyer, J. L., Bünger, W., and Reinhold-Hurek, B. (2017). Bradyrhizobium namibiense sp. nov., a symbiotic nitrogen-fixing bacterium from root nodules of Lablab purpureus, hyacinth bean, in Namibia. Int. J. Syst. Evol. Microbiol. 67, 4884-4891. doi: 10.1099/ijsem.0.002039

Grönemeyer, J. L., Chimwamurombe, P., and Reinhold-Hurek, B. (2015a). Bradyrhizobium subterraneum sp. nov., a symbiotic nitrogen-fixing bacterium from root nodules of groundnuts. Int. J. Syst. Evol. Microbiol. 65, 3241-3247. doi: 10.1099/ijsem.0.000403

Grönemeyer, J. L., Hurek, T., Bünger, W., and Reinhold-Hurek, B. (2016). Bradyrhizobium vignae sp. nov., a nitrogen-fixing symbiont isolated from effective nodules of Vigna and Arachis. Int. J. Syst. Evol. Microbiol. 66, 62-69. doi: 10.1099/ijsem.0.000674

Grönemeyer, J. L., Hurek, T., and Reinhold-Hurek, B. (2015b). Bradyrhizobium kavangense sp. nov., a symbiotic nitrogen-fixing bacterium from root nodules of traditional Namibian pulses. Int. J. Syst. Evol. Microbiol. 65, 4886-4894. doi: 10.1099/ijsem.0.000666

Grönemeyer, J. L., Kulkarni, A., Berkelmann, D., Hurek, T., and ReinholdHurek, B. (2014). Identification and characterization of rhizobia indigenous to the Okavango region in Sub-Saharan Africa. Appl. Environ. Microbiol. 80, 7244-7257. doi: 10.1128/AEM.02417-14

Gröngröft, A., Luther-Mosebach, J., Landschreiber, L., and Eschenbach, A. (2013). Cusseque soils. Biodivers. Ecol. 5, 51-54. doi: 10.7809/b-e.00245

Große, L. M., Kowalski, B., Domptail, S., and Eigner, A. (2013). Seronga - The people. Biodivers. Ecol. 5, 147-158. doi: 10.7809/b-e.00270

Heath, K. D., and Tiffin, P. (2009). Stabilizing mechanisms in a legume-rhizobium mutualism. Evolution 63, 652-662. doi: 10.1111/j.1558-5646.2008.00582.x

Hollowell, A. C., Regus, J. U., Turissini, D., Gano-Cohen, K. A., Bantay, R., Bernardo, A., et al. (2016). Metapopulation dominance and genomic-island acquisition of Bradyrhizobium with superior catabolic capabilities. Proc. Biol. Sci. 283:20160496. doi: 10.1098/rspb.2016.0496

Horn, K., Parker, I. M., Malek, W., Rodriguez-Echeverria, S., and Parker, M. A. (2014). Disparate origins of Bradyrhizobium symbionts for invasive populations of Cytisus scoparius (Leguminosae) in North America. FEMS Microbiol Ecol. 89, 89-98. doi: 10.1111/1574-6941.12335
Kottek, M., Grieser, J., Beck, C., Rudolf, B., and Rubel, F. (2006). World map of the Köppen-Geiger climate classification updated. Meteorol. Z. 15, 259-263. doi: 10.1127/0941-2948/2006/0130

Kowalski, B., Azebaze, N., Domptail, S., Große, L. M., and Pröpper, M. (2013). Mashare - The people. Biodivers. Ecol. 5, 121-128. doi: 10.7809/b-e.00263

Kuykendall, L. D. (2005). "Genus Bradyrhizobium," in Bergey's Manual of Systematic Bacteriology, 2nd edn, ed G. M. Garrity (New York, NY: Springer Verlag), 438-443.

Law, I. J., Botha, W. J., Majaule, U. C., and Phalane, F. L. (2007). Symbiotic and genomic diversity of 'cowpea' bradyrhizobia from soils in Botswana and South Africa. Biol. Fertil. Soils 43, 653-663. doi: 10.1007/s00374-006-0145-y

Lemaire, B., Dlodlo, O., Chimphango, S., Stirton, C., Schrire, B., Boatwright, J. S., et al. (2015). Symbiotic diversity, specificity and distribution of rhizobia in native legumes of the Core Cape Subregion (South Africa). FEMS Microbiol. Ecol. 91, 1-17. doi: 10.1093/femsec/fiu024

Lewin, A., Rosenberg, C., H. Meyer, Z. A., Wong, C. H., Nelson, L., Manen, J. F., et al. (1987). Multiple host-specificity loci of the broad host-range Rhizobium sp. NGR234 selected using the widely compatible legume Vigna unguiculata. Plant Mol. Biol. Rep. 8, 447-459. doi: 10.1007/BF00017990

Li, Q. Q., Wang, E. T., Zhang, Y. Z., Zhang, Y. M., Tian, C. F., Sui, X. H., et al. (2011). Diversity and biogeography of rhizobia isolated from root nodules of Glycine max grown in Hebei Province, China. Microb. Ecol. 61, 917-931. doi: 10.1007/s00248-011-9820-0

Linder, H. P. (2001). Plant diversity and endemism in sub-Saharan tropical Africa. J. Biogeogr. 28, 169-182. doi: 10.1046/j.1365-2699.2001.00527.x

Martins, L. M. V., Neves, M. C. P., and Rumjanek, N. G. (1997). Growth characteristics and symbiotic efficiency of rhizobia isolated from cowpea nodules of the north-east region of Brazil. Soil Biol. Biochem. 29, 1005-1010. doi: 10.1016/S0038-0717(96)00215-5

Michel, D. C., Passos, S. R., Simoes-Araujo, J. L., Baraúna, A. C., da Silva, K., Parma, M. M., et al. (2017). Bradyrhizobium centrolobii and Bradyrhizobium macuxiense sp. nov. isolated from Centrolobium paraense grown in soil of Amazonia, Brazil. Arch. Microbiol. 199, 657-664. doi: 10.1007/s00203-017-1340-y

Mpeperiki, S., and Pompi, I. (2003). "Promoting new BNF technologies among smallholder farmers: A success story from Zimbabwe," in Grain Legumes and Green Manures for Soil Fertility in Southern Africa: Taking Stock of Progress. Proceedings of a Conference Held 8-11 October 2002 at Vumba, Zimbabwe, ed S. R. Waddington (Harare: Soil Fertil Net and CIMMYT-Zimbabwe), 33-38.

Mpepereki, S., Wollum Il, A. G., and Makonese, F. (1996). Diversity in symbiotic specificity of cowpea rhizobia indigenous to Zimbabwean soils. Plant Soil 186, 167-171. doi: 10.1007/BF00035071

Munévar, F., and Wollum, A. G. (1981). Growth of Rhizobium japonicum strains at temperatures above $27^{\circ} \mathrm{C}$. Appl. Environ. Microbiol. 42, 272-276.

Ndungu, S. M., Messmer, M. M., Ziegler, D., Gamper, H. A., Mészáros, É., Thuita, M., et al. (2018). Cowpea (Vigna unguiculata L. Walp) hosts several widespread bradyrhizobial root nodule symbionts across contrasting agroecological production areas in Kenya. Agric. Ecosyst. Environ. 261, 161-171. doi: 10.1016/j.agee.2017.12.014

Ormeno-Orrillo, E., Rogel-Hernandez, M. A., Lloret, L., López-López, A., Martinez, J., Barois, I., et al. (2012). Change in land use alters the diversity and composition of Bradyrhizobium communities and led to the introduction of Rhizobium etli into the tropical rain forest of Los Tuxtlas (Mexico). Microb. Ecol. 63, 822-834. doi: 10.1007/s00248-011-9974-9

Parker, M. A. (2015). The spread of Bradyrhizobium lineages across host legume clades: from Abarema to Zygia. Microb. Ecol. 69, 630-640. doi: 10.1007/s00248-014-0503-5

Parté, A. C. (2014). LPSN-list of prokaryotic names with standing in nomenclature. Nucleic Acids Res. 42, D613-D616. doi: 10.1093/nar/gkt1111

Perez-Raminez, N. O., Rogel, M. A., Wang, E., Castellanos, J. Z., and MartinezRomero, E. (1998). Seeds of Phaseolus vulgaris bean carry Rhizobium etli FEMS Microbiol. Ecol. 26, 289-296.

Petersen, A., Gröngröft, A., and Miehlich, G. (2010). Methods to quantify the pedodiversity of $1 \mathrm{~km}^{2}$ areas - results from southern African drylands. Geoderma 155, 140-146. doi: 10.1016/j.geoderma.2009.07.009

Porter, S. S., Stanton, M. L., and Rice, K. J. (2011). Mutualism and adaptive divergence: co-invasion of a heterogeneous grassland by an exotic legumerhizobium symbiosis. PLoS ONE 6:e27935. doi: 10.1371/journal.pone.0027935 
Pröpper, M., Gröngröft, A., Falk, T., Eschenbach, A., Fox, T., Gessner, U., et al. (2010). "Causes and perspectives of land-cover change through expanding cultivation in Kavango," in Biodiversity in Southern Africa 3: Implications for landuse and management, eds N. Jürgens, U. Schmiedel, and T. Hoffman. (Göttingen, Windhoek: Klaus Hess), 2-31.

Pröpper, M., Gröngröft, A., Finckh, M., Stirn, S., De Cauwer, V., Lages, F., et al. (2015). The Future Okavango: Findings, Scenarios and Recommendations for Action. Hamburg: University of Hamburg.

Pule-Meulenberg, F. (2014). "Root-nodule bacteria of legumes growing in semiarid African soils and other areas of the world," in Bacterial Diversity in Sustainable Agriculture, ed D. K. Meheshwari (Heidelberg; New York, NY; Dordrecht; London: Springer), 101-130.

Pule-Meulenberg, F., Belane, A. K., Krasova-Wade, T., and Dakora, F. D. (2010). Symbiotic functioning and bradyrhizobial biodiversity of cowpea (Vigna unguiculata L. Walp.) in Africa. BMC Microbiol. 10:89. doi: 10.1186/1471-2180-10-89

Puozaa, D. K., Jaiswal, S. K., and Dakora, F. D. (2017). African origin of Bradyrhizobium populations nodulating Bambara groundnut (Vigna subterranea L. Verdc) in Ghanaian and South African soils. PLoS ONE 12:e0184943. doi: 10.1371/journal.pone.0184943

Risal, C. P., Yokoyama, T., Ohkama-Ohtsu, N., Djedidi, S., and Sekimoto, H. (2010). Genetic diversity of native soybean bradyrhizobia from different topographical regions along the southern slopes of the Himalayan Mountains in Nepal. Syst. Appl. Microbiol. 33, 416-425. doi: 10.1016/j.syapm.2010.06.008

Roughley, R. J. (1970). The influence of root temperature, Rhizobium strain and host selection on the structure and nitrogen-fixing efficiency of the root nodules of Trifolium subterraneum. Ann. Bot. 34, 631-646. doi: 10.1093/oxfordjournals.aob.a084397

Rudebjer, P., Chakeredza, S., Dansi, A., Ekaya, W., Ghezae, N., Aboagye, L. M., et al. (2013). Beyond commodity crops: strengthening young scientists' capacity for research on underutilised species in Sub-Saharan Africa. Acta Horticult. 979, 577-588. doi: 10.17660/ActaHortic.2013.979.62

Sarr, P. S., Yamakawa, T., Saeki, Y., and Guisse, A. (2011). Phylogenetic diversity of indigenous cowpea bradyrhizobia from soils in Japan based on sequence analysis of the 16S-23S rRNA internal transcribed spacer (ITS) region. Syst. Appl. Microbiol. 34, 285-292. doi: 10.1016/j.syapm.2010.11.021

Sprent, J. I., Ardley, J. K., and James, E. K. (2013). From North to South: a latitudinal look at legume nodulation processes. South Afr. J. Bot. 89, 31-41. doi: 10.1016/j.sajb.2013.06.011

Sprent, J. I., Odee, D. W., and Dakora, F. D. (2010). African legumes: a vital but under-utilized resource. J. Exp. Bot. 61, 1257-1265. doi: 10.1093/jxb/erp342

Steenkamp, E. T., Stepkowski, T., Przymusiak, A., Botha, W. J., and Law, I. J. (2008). Cowpea and peanut in southern Africa are nodulated by diverse Bradyrhizobium strains harboring nodulation genes that belong to the large pantropical clade common in Africa. Mol. Phylogenet. Evol. 48, 1131-1144. doi: 10.1016/j.ympev.2008.04.032

Stepkowski, T., Hughes, C. E., Law, I. J., Markiewicz, L., Gurda, D., Chlebicka, A., et al. (2007). Diversification of lupine Bradyrhizobium strains: evidence from nodulation gene trees. Appl. Environ. Microbiol. 73, 3254-3264. doi: 10.1128/AEM.02125-06

Stepkowski, T., Moulin, L., Krzyzanska, A., McInnes, A., Law, I. J., and Howieson, J. (2005). European origin of Bradyrhizobium populations infecting lupins and serradella in soils of Western Australia and South Africa. Appl. Environ. Microbiol. 71, 7041-7052. doi: 10.1128/AEM.71.11.7041-7052.2005

Stepkowski, T., Watkin, E., McInnes, A., Gurda, D., Gracz, J., and Steenkamp, E. T. (2012). Distinct Bradyrhizobium [corrected] communities nodulate legumes native to temperate and tropical monsoon Australia. Mol. Phylogenet. Evol. 63, 265-277. doi: 10.1016/j.ympev.2011.12.020

Suzuki, Y., Adhikari, D., Itoh, K., and Suyama, K. (2014). Effects of temperature on competition and relative dominance of Bradyrhizobium japonicum and Bradyrhizobium elkanii in the process of soybean nodulation. Plant Soil 374, 915-924. doi: 10.1007/s11104-013-1924-5
Trytsman, M., Westfall, R. H., Breytenbach, P. J. J., Calitz, F. J., and van Wyk, A. E. (2016). Diversity and biogeographical patterns of legumes (Leguminosae) indigenous to southern Africa. Phytokeys 53-96. doi: $10.3897 /$ phytokeys.70.9147

van Berkum, P., and Fuhrmann, J. J. (2000). Evolutionary relationships among the soybean bradyrhizobia reconstructed from 16S rRNA gene and internally transcribed spacer region sequence divergence. Int. J. Syst. Evol. Microbiol. 50, 2165-2172. doi: 10.1099/00207713-50-6-2165

Vinuesa, P., Leon-Barrios, M., Silva, C., Willems, A., Jarabo-Lorenzo, A., Perez-Galdona, R., et al. (2005a). Bradyrhizobium canariense sp. nov., an acid-tolerant endosymbiont that nodulates endemic genistoid legumes (Papilionoideae: Genisteae) from the Canary Islands, along with Bradyrhizobium japonicum bv. genistearum, Bradyrhizobium genospecies alpha and Bradyrhizobium genospecies beta. Int. J. Syst. Evol. Microbiol. 55, 569-575. doi: 10.1099/ijs.0.63292-0

Vinuesa, P., Rojas-Jimenez, K., Contreras-Moreira, B., Mahna, S. K., Prasad, B. N., Moe, H., et al. (2008). Multilocus sequence analysis for assessment of the biogeography and evolutionary genetics of four Bradyrhizobium species that nodulate soybeans on the asiatic continent. Appl. Environ. Microbiol. 74, 6987-6996. doi: 10.1128/AEM.00875-08

Vinuesa, P., Silva, C., Werner, D., and Martinez-Romero, E. (2005b). Population genetics and phylogenetic inference in bacterial molecular systematics: the roles of migration and recombination in Bradyrhizobium species cohesion and delineation. Mol. Phylogenet. Evol. 34, 29-54. doi: 10.1016/j.ympev.2004. 08.020

Wade, T. K., Le Quere, A., Laguerre, G., N'Zoue, A., Ndione, J. A., Dorego, F., et al. (2014). Eco-geographical diversity of cowpea bradyrhizobia in Senegal is marked by dominance of two genetic types. Syst. Appl. Microbiol. 37, 129-139. doi: 10.1016/j.syapm.2013.10.002

Wang, R., Chang, Y. L., Zheng, W. T., Zhang, D., Zhang, X. X., Sui, X. H., et al. (2013). Bradyrhizobium arachidis sp. nov., isolated from effective nodules of Arachis hypogaea grown in China. Syst. Appl. Microbiol. 36, 101-105. doi: 10.1016/j.syapm.2012.10.009

Willems, A., Doignon-Bourcier, F., Goris, J., Coopman, R., de Lajudie, P., De Vos, P., et al. (2001). DNA-DNA hybridization study of Bradyrhizobium strains. Int. J. Syst. Evol. Microbiol. 51, 1315-1322. doi: 10.1099/00207713-51-4-1315

Zhang, H., Prithiviraj, B., Charles, T. C., Driscoll, B. T., and Smith, D. L. (2003). Low temperature tolerant Bradyrhizobium japonicum strains allowing improved nodulation and nitrogen fixation of soybean in a short season (cool spring) area. Eur. J. Agron. 19, 205-213. doi: 10.1016/S1161-0301(02)00038-2

Zhang, S., Xie, F., Yang, J., and Li, Y. (2011). Phylogeny of bradyrhizobia from Chinese cowpea miscellany inferred from 16S rRNA, atpD, glnII, and 16S-23S intergenic spacer sequences. Can. J. Microbiol. 57, 316-327. doi: 10.1139/w11-008

Zhang, Y. F., Wang, E. T., Tian, C. F., Wang, F. Q., Han, L. L., Chen, W. F., et al. (2008). Bradyrhizobium elkanii, Bradyrhizobium yuanmingense and Bradyrhizobium japonicum are the main rhizobia associated with Vigna unguiculata and Vigna radiata in the subtropical region of China. FEMS Microbiol. Lett. 285, 146-154. doi: 10.1111/j.1574-6968.2008.0 1169.x

Conflict of Interest Statement: The authors declare that the research was conducted in the absence of any commercial or financial relationships that could be construed as a potential conflict of interest.

Copyright $\odot 2018$ Grönemeyer and Reinhold-Hurek. This is an open-access article distributed under the terms of the Creative Commons Attribution License (CC BY). The use, distribution or reproduction in other forums is permitted, provided the original author(s) and the copyright owner(s) are credited and that the original publication in this journal is cited, in accordance with accepted academic practice. No use, distribution or reproduction is permitted which does not comply with these terms. 